She has worked as Student Needs Coordinator at both Hervey Bay Senior College and The University of Southern Queensland.

She is also a committed artist and mother, and spends her time between her children and artwork, Ms Quivooy said.

Ms Henderson's paintings have been described as contemporary in style with a particular emphasis on sea creatures as subject matter.

The artist-in-residence program was made possible through funding from the school's Aboriginal Student Support and Parent Awareness
Committee and the Bundaberg Art Society Inc.

Ms Quivooy said she was keen for other schools to hear of the success of Bundaberg State High's program.

'By sharing our positive experiences we may encourage other schools and educators to take on a cultural challenge,' she said.

Editor's Note: Thesethreeshort articles originally appeared in Education Views on 9 December 1994 and are reprinted with permission of the Public and Media Relations Branch of the Queensland Department of Education.

\title{
NEWS: UQ Aboriginal and Torres Strait Islander Student Participation Project
}

The Aboriginal and Torres Strait Islander Studies Unit at The University of Queensland has identified the need to develop detailed monitoring strategies to gauge the participation and academic performance of indigenous students at The University of Queensland. To reach this goal the Unit has launched a project which aims to investigate the participation and post-study destinations of Aboriginal and Torres Strait Islander students.

The objectives of the project are:

- to determine the major trends associated with Aboriginal and Torres Strait Islander student participation and academic performance

- to explain these trends by way of a survey of past and present students, and to establish mechanisms to monitor the future
performance of students.

The principal motivation for undertaking the project is to develop the capacity to monitor the effectiveness of University strategies and approaches to Aboriginal and Torres Strait Islander education policy. It is expected that this capability will enable the Unit to identify strategies for assisting students to complete tertiary studies while fulfilling their cultural obligations.

For further information, or any input into the project, please contact Peter Christensen at the Aboriginal and Torres Strait Islander Studies Unit, University of Queensland, Brisbane, Queensland, 4072 , or by phone on (07) 3656958 or facsimile (07) 3652359 .

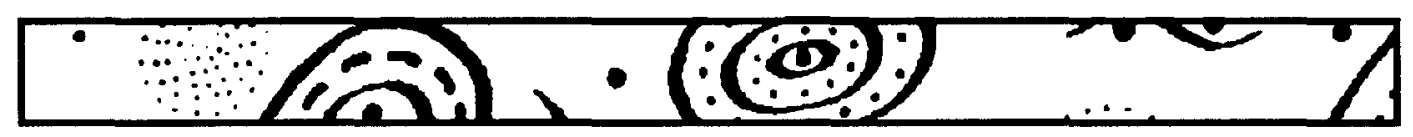

